\title{
Application of zero-thickness interface elements to sanding prediction analysis
}

\author{
Daniel Garolera ${ }^{\mathrm{a}}$, Ignacio $\mathrm{Carol}^{\mathrm{a}}$, Panos Papanastasiou ${ }^{\mathrm{b}}$ \\ ${ }^{a}$ Department of Civil and Environmental Engineering, Division of Geotechnical Engineering, BarcelonaTech (UPC), campus Nord, 08034 \\ Barcelona, Spain \\ ${ }^{b}$ Department of Civil and Environmental Engineering, University of Cyprus, Nicosia, Cyprus
}

\begin{abstract}
A computational micromechanical analysis based on zero thickness interface elements for modelling solid prediction in hydrocarbon reservoir sandstones is presented. The model is capable of modelling localization of deformation, disintegration and cracking of cemented rock formation that leads to initiation and continuous sand production during hydrocarbon production and reservoir depletion. Using only few physical parameters, the model is calibrated at the macroscale by reproducing the typical behaviour of geomaterials in compression element tests that is characterized by transition from brittle dilatant to ductile compactant behaviour with increasing confining stress. In the presented application presented, the model was calibrated first using the results of two triaxial tests performed on samples that were recovered from a deep well and then a sand production analysis was carried out. The model predictions are compared well with the experimental results of thick wall cylinder tests. The proposed methodology is very promising as it can predict not only the initiation of sanding, but also the continuous produced sand volumes under geometry changing conditions which is still a challenging research problem.
\end{abstract}

Keywords: Sand production prediction, sanding, zero-thickness interfaces, micromechanics, localization, cracking

\section{Introduction}

During hydrocarbon production from weakly consolidated formations, sanding, which is an unwanted phenomenon, may occur. Sanding appears during high production rate and may be accelerated with reservoir depletion due to the increase in the effective stresses. Sanding may cause a series of problems, from erosion of equipment, cleaning and disposal of contaminated produced sand to even wellbore collapse. These problems are very costly, especially, in offshore deep-water wells due to limited handling space, safety issues and expensive intervention for workover.

In consolidated formations sanding follows rock failure due to the increase of the effective stresses caused first by the pressure drawdown near a flowing well and depletion at the reservoir scale. Rock failure appears in the form of deformation damage, disaggregation and cracking of the rock fabric at the cavity wall of the wellbore and/or perforations. Disaggregation is caused by the loss of cohesion between grains whereas cracking may involve cluster of grains or larger isolated areas that are dispatched and transported and eroded by fluid flow, resulting in the production of solid particles. Limited amount of sand production has the benefit of removing permeability damages due to drilling, enhancing the hydrocarbon production. However, poor prediction of this phenomenon can lead to

Email addresses: daniel.garolera@upc.edu (Daniel Garolera), ignacio.carol@upc.edu (Ignacio Carol), panospap@ucy.ac.cy (Panos Papanastasiou) uncontrollable sanding with the severe consequences mentioned above.

In practice, the problem of sand production is avoided by completing the wells after drilling with sand control equipment which includes expensive screen-filters prepacked with gravel or gravel-packing placed in the annulus between screens and wellbore wall. Sand control completion techniques are not only expensive, but may block the permeability at the filters impairing the production or the filters may even fail to control sanding. For this reason, a prediction tool is needed to provide information on the risk of sanding, how severe is expected the problem to be and whether sand control is needed (Han, 2003). Mathematical models which can predict the flowing wellbore pressure and the stage of depletion at which sanding will occur are useful tools for screening the cases for sand control. The objective is to develop sanding predictive tools which in connection with reservoir simulations will maximize the production of hydrocarbons maintaining sand production to acceptable limits.

The first attempts to model sanding were based on elastic stress analysis that takes into account the pore pressure and wellbore pressure and simple failure criterion which compares the tangential stress at the hole with uniaxial compressive strength of the formation. Those models were later extended to account for anisotropic insitu stresses (Papamichos, 2010), elastoplasticity with different material models and stress interaction with FEM analysis (Morita, 2004; Papamichos and Furui, 2019). Most 
of these models can predict only the initiation of sanding in open hole completions. Sanding in wellbore perforated completions is more challenging as due to the small size of the perforation, the rock microstructure plays a significant role. This was supported by thick wall cylinder tests (TWC) where it was found that the external pressure required to induce failure is much higher for small holes than for large holes (Haimson and Herrick, 1989; Tronvoll et al., 1993; Papamichos and den Hoek, 1995). In fact, the most dominant factor in cylinder strength in the range of perforation size (diameter less than $5 \mathrm{~cm}$ ) is the scale effect. Standard continuum models cannot easily account for those effects as the governing equations can be written in a dimensionless form, predicting the same failure pressure for all geometrically similar cylinders. Predicting scale effects in continuum models is possible but requires introducing advanced numerical artifacts which complicate the analysis and are not always totally effective. Alternatively, often in practise calibration of the continuum models is done on TWC tests that have the same hole size as the field perforations. The present model has the capability to predict the scale effect (Garolera et al., 2019). Earlier works to model the failure of perforations by localization of deformation and accounting for the scale effect were done using higher order continua such as Cosserat continuum (Papanastasiou and Vardoulakis, 1989, 1992; Papamichos, 2010) and gradient plasticity (Zervos et al., 2001; Papanastasiou and Zervos, 2004). The scale effect in perforation collapse was also modelled combining fracture mechanics and layer buckling theories (Papanastasiou and Thiercelin, 2011). Nevertheless, in all these studies no flowing conditions and removal of the failed areas after first breakouts were considered. Another approach, known as erosion models, based on fluid-flow, mass balances and erosion mechanisms was developed for weakly consolidated formations (Vardoulakis et al., 1996; Stavropoulou et al., 1998; Papamichos and Stavropoulou, 1998; Papamichos et al., 2001; Gravanis et al., 2015) but those studies were essentially 1D ignoring any changes of geometry after surface erosion.

An alternative physically sound approach is based on the discrete element method (DEM) which can produce interesting results from a mechanical point of view, as they are able to reproduce the discrete nature of granular rock and realistic failure kinematics. Despite the potential of DEM there are still limitations related to the modelling of the fluid flow, which can be performed separately on a background FEM mesh (Jensen et al., 2001; Li et al., 2006). In summary, each of the above methods have their own drawbacks and limitations mainly related to model parameter calibration, changing geometry and the size of the real applications. Rahmati et al. (2013) presented a literature review on both numerical and analytical sand production models.

In the present article, a new micromechanical approach is proposed for the study of sand production processes. The modelling approach is based on the explicit repre- sentation of the rock micro-structure and the use of zerothickness interface elements. In this way, it is possible to avoid artificially complex theories and to overcome the limitations in the kinematics of deformation of continuum media in representing advanced state of failure due to the propagation of cracks discontinuities, eroded and failed areas. An advantage of this approach is also that this framework provides the possibility of obtaining a unified solution to the flow problem in the same domain where the open cracks, discontinuities, eroded and failed areas become enhanced permeability channels (Segura and Carol, 2008a,b; Garolera, 2017), though the results presented in this article are restricted to a solid mechanics study as a first approach of the problem. Nevertheless, the analysis in its present form can be used to predict the rock failure in consolidated rocks which is the first stage of sanding; if rock failure is avoided no sanding will occur. The methodology was originally developed for heterogeneous materials such as concrete (López, 1999; Caballero et al., 2006), and then its application has been extended to other materials including rock (Garolera et al., 2005, 2011). The numerical aspects of the micro-mechanical model employed are described in detail in Garolera et al. (2019), while the present paper focuses on the application of the same model to the $2 \mathrm{D}$ analysis in plane strain of a thick wall cylinder crosssection, for comparison with thick wall cylinder (TWC) tests used for simulating failure of perforations (Fig. 1). The analysis is performed in plane strain, although in the approach proposed plane stress or plane strain does not make a fundamental difference with regard to the failure predictions, since out-of-plane stresses do not participate in the interface constitutive behaviour governing failure criterion.

Although real field sand production processes obviously involve the presence of fluid and a realistic analysis would require a coupled HM calculation involving physical time increments, the current study aims at reproducing the purely mechanical behaviour of TWC tests because this seems to be a relatively common test to evaluate rock susceptibility to sand production, and experimental results are available to compare the numerical predictions. In this type of tests, the fluid circulates along the specimen inner hole with the only purpose of removing the sand grains that are getting detached as the external load is increased to failure, and the external load factor may be considered as a fictitious time variable. Application of the model to the coupled analysis of sand production in field conditions is left for future studies, and therefore out of the scope of the present paper.

After the short introduction and literature review on sanding problem presented above, the paper content is organised as follows: in Section 2 the main characteristics of the model are briefly presented. Section 3 describes the application of the microstructural analysis, first to the calibration of the model with real rock data and then to the numerical simulation of thick wall cylinder tests and the comparison with the experimental results. Finally, some 


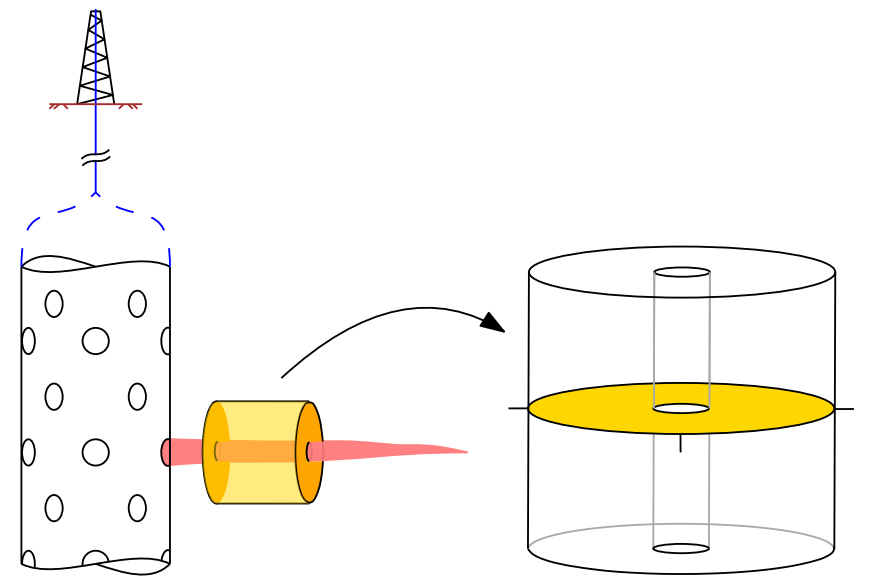

Figure 1: Schematic drawing of a borehole with horizontal perforations generated with shape charges perforation guns. The $2 \mathrm{D}$ cross-section subject to the numerical analysis in the context of this study, is highlighted in diagram on the right.

concluding remarks on the work presented are included in Section 4.

\section{Microstructural approach to sand prediction}

This section presents briefly a micromechanical approach based on the Finite Element Method with zero-thickness interface elements $(\mathrm{FEM}+\mathrm{z})$ for analysis of failure in cemented granular materials, such as sandstones which experience inter-granular and intra-granular cracking and fracturing under loading.

This modelling approach is capable of reproducing this complex behaviour using only few physical parameters, at the expense of discretizing the grain microstructure explicitly, instead of phenomenological parameters used in the classical continuum. This approach has been used successfully in previous studies in modelling the mechanical behaviour of quasi-brittle materials such concrete under different loading conditions (Carol et al., 2001; López et al., 2008; Caballero et al., 2006). A detailed description of the methodology and its implementation for the representation of sanstone rock can be found in Garolera et al. (2019)

\subsection{Zero-thickness interface elements}

Interface or joint elements of the zero-thickness type (Goodman et al., 1968) are a special kind of finite elements introduced between adjacent continuum elements (Fig. 2). Their singular feature is that they have one less dimension than the standard continuum elements, lines in $2 \mathrm{D}$ and surfaces in $3 \mathrm{D}$. The integration of these elements is performed over the domain represented by the interface line or surface ("mid-plane"), and with the help of a local set of orthogonal axes. Due to the reduction of dimensions, the interface constitutive behaviour is formulated in

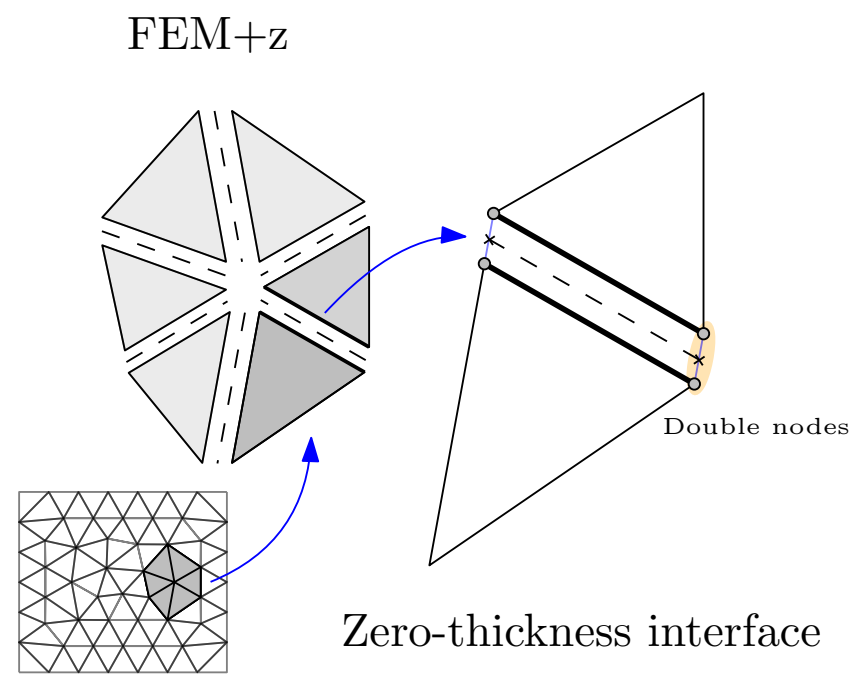

Figure 2: Zero-thickness interface element description. (left) Example of triangle FEM $+\mathrm{Z}$ mesh; and (right) detail of the definition of a linear interface embedded between two triangular continuum finite elements.

terms of the jump of the main variable across the midplane of the interface, and the corresponding force-type conjugate variable. In the standard mechanical problem, those variables are the normal and tangential components of the relative displacements, together with their counterpart stress tractions on the interface plane.

Although zero-thickness interface elements were initially proposed to represent pre-existing discontinuities or material interfaces of known fixed location and frictional behaviour (Goodman et al., 1968; Gens et al., 1989), their application was later extended to represent newly developing cracks of an initially uncracked media (e.g., Rots (1988); Carol et al. (2001)). In this context, the approach consists of inserting interface elements along all (or a subset of all) the mesh lines (FEM+z, Fig. 2), and equipping them with a fracture-based constitutive law with the initial strength of the uncracked material (Garolera et al., 2011).

\subsection{Discretization of material microstructure}

The microstructure of sandstone rock is represented by a number of polygonal grains made of continuum elements, that are separated by zero-thickness interface elements. These interface elements are equipped with an appropriate constitutive law to represent inter-granular fracture and friction. On the other hand, it is known that sandstone grains are not perfectly matching polygons but more round-shaped particles leaving corner spaces between them that are filled with a cementing material, see Fig. 3a. This motivates to introduce a second set of "intragranular" interfaces connecting the boundaries of each grain to its center, in order to approximately represent the possibility of cement cracking and avoid excessively tortuous crack trajectories that might be obtained if they could fol- 


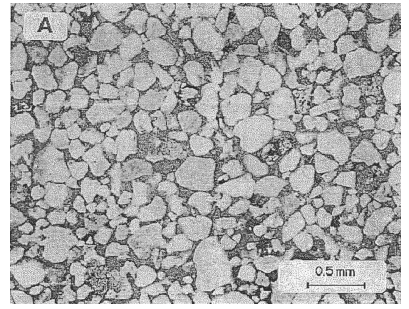

a) Real rock microstructure

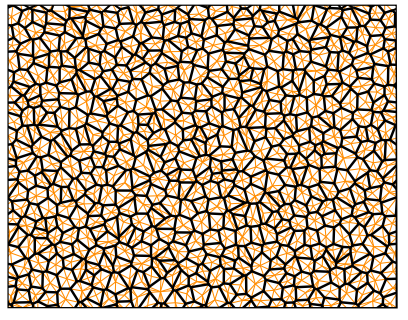

b) Idealized microstruture
Figure 3: Comparison of the structure of a real sandstone with the descritized model and numerical model structure: a) Micro-photograph from a sandstone sample and b) the interface layout of idealized model with FEM+z. In dark, contacts between grains and, in pale, potential intra-granular crack paths.

low exclusively the inter-granular darker lines in Fig. 3.b A numerical study of the sensitivity of the overall material mechanical behavior to the different ratios between intra-granular and inter-granular strength parameters can be found in Garolera et al. (2019).

Another feature of this approach is that it naturally introduces length/scale effects. A first geometric length scale is introduced by the grain size itself. Also, a second mechanical effect of the size is provided by the fact that the interface constitutive law is formulated in terms of relative displacements (rather than strains), and therefore it dissipates energy per unit area of crack (instead of unit volume of the continuum) and includes fracture energies $G_{f}^{I}$ and $G_{f}^{I I a}$ as two parameters of the model. As is well known, fracture energy is directly related to fracture toughness, and a combination of fracture toughness and material strength introduces a characteristic length scale in the problem (e.g see Bažant and Planas (1998), or Papanastasiou and Thiercelin (2011)).

The generation of micro-geometries and the corresponding FE meshes is carried out with an automatic mesh generation procedure in which the grains of approximately equal size are distributed randomly and the inter-granular phases are idealized as contacts between grains. The process is applied in the following five steps (see Fig. 4): 1. Random distribution of initial grid of points 2. A Delaunay triangulation with vertices generated in step 1. 3. A Voronoi tessellation is generated from the Delaunay triangulation. Here a first filtering is done to eliminate the small sides for avoiding elements with poor geometric aspect ratios. 4. Subdivision of polygons in triangular continuum elements. 5. Clipping the overall triangular mesh according to the final geometry of the problem (e.g. rectangle in case of tension/compression specimens, or circular in case of the Thick Wall Cylinder test (TWC). Additionally, in this step zero-thickness interface elements are introduced between continuum elements. A second filtering is performed at this point to avoid small sides and quadrangular elements in the boundary zone.

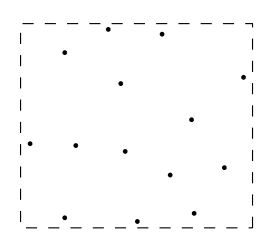

a) Grid of points

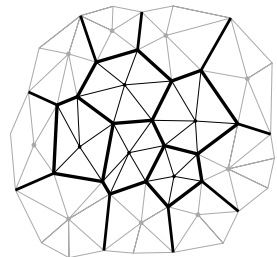

d) Element discretization

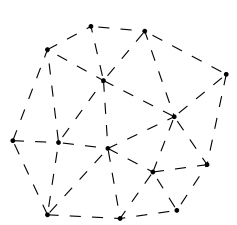

b) Delanuay triangulation

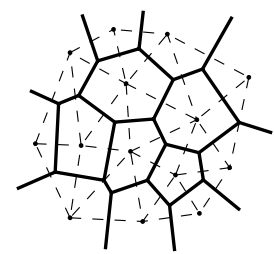

c) Voronoi tessellation
Figure 4: Delaunay-Voronoi based mesh generation method

\subsection{Interface constitutive law}

Two mechanical constitutive laws for interfaces were used in this study, expressed by the relationship between the relative displacements vector $(\mathbf{r})$ with components normal and shear relative displacements $\left(r_{n}, r_{t}\right)$ and the corresponding stress tractions vector $\left(\boldsymbol{\sigma}_{\mathrm{J}}\right)$ on the interface plane with components normal and shear stresses $\left(\sigma_{n}, \tau\right)$. All those variables are defined on the mid-plane of the interface using a local reference system and the sign criterion followed is tension positive as usual in continuum mechanics. The material behaviour is based on the basic elastic relationship and a cracking law. The elastic relation is defined by the two parameters, the normal $\left(K_{n}\right)$ and tangential $\left(K_{t}\right)$ stiffness coefficients, which in matrix form is written.

$$
\boldsymbol{\sigma}_{\mathrm{J}}=\mathbf{D}_{\mathrm{J}}^{e l} \mathbf{r} \Rightarrow\left(\begin{array}{c}
\sigma_{n} \\
\tau
\end{array}\right)=\left(\begin{array}{cc}
K_{n} & 0 \\
0 & K_{t}
\end{array}\right)\left(\begin{array}{l}
r_{n} \\
r_{t}
\end{array}\right)
$$

The interface constitutive relation is expressed by an elasto-plastic law in which the state variable is formulated in terms of energy and it includes concepts of fracture mechanics and fracture energy parameters (Carol and Prat, 1990, 1995; Carol et al., 1997, 2001; López, 1999; Caballero et al., 2008). The model has been described in detail elsewhere, and for this reason here only the main features are briefly summarized. In the current study, the following three-parameter hyperbolic fracture surface (Caballero et al., 2008) is used:

$$
F\left(\boldsymbol{\sigma}_{\mathrm{J}}, \mathbf{p}\left(W^{c r}\right)\right)=\sigma_{n} \tan \phi+\sqrt{\tau^{2}+(C-\chi \tan \phi)^{2}}-C
$$

where $\tau, \sigma_{n}$ are the shear stress and normal stresses, and $\mathbf{p}$ is the vector collecting the three strength parameters defining geometrically the surface: $\chi$ is the horizontal coordinate of the vertex of the hyperbola (tensile strength), and $C$ and $\tan \phi$ are the cohesion and the friction angle parameters defined by the asymptote to the hyperbola, see Fig. 5. In order to represent the decrease of interface 


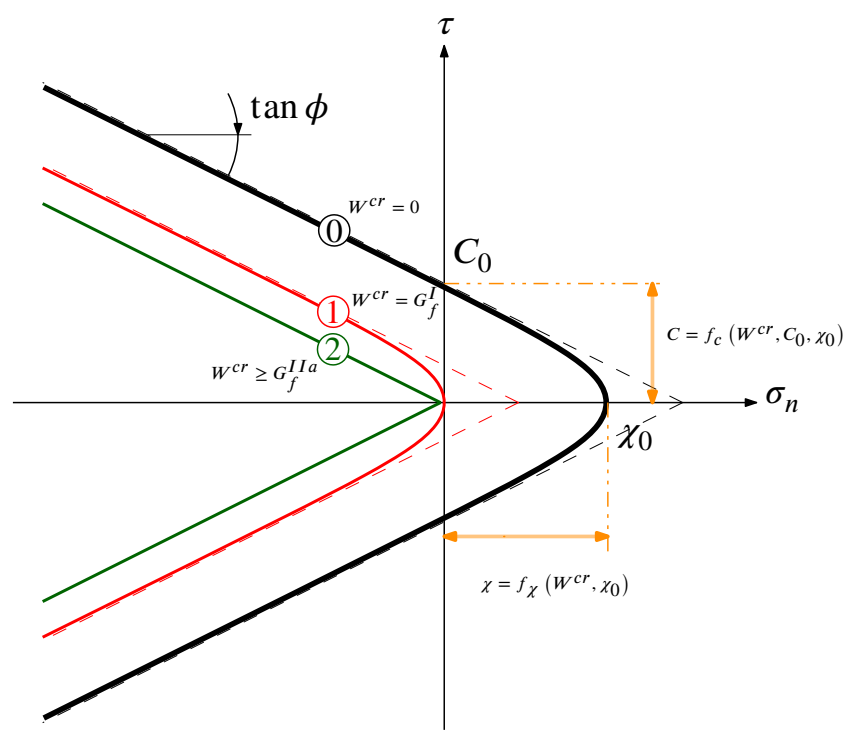

Figure 5: Illustration of the constitutive model of the interface, fracture surface at three stages of evolution: initial state when $W^{c r}=0$ (curved marked "0"), degraded state when all tensile capacity is exhausted, $W^{c r}=G_{f}^{I}$ (curved marked "1"), and totally degraded state under shear-compression $W^{c r}=G_{f}^{I I a} /($ curved marked "2").

strength as cracking progresses, softening laws are assumed for the three strength parameters, which evolve in terms of the work spent in the fracture process, $W^{c r}$. Such evolution laws incorporate two parameters that control the two fracture modes: the classical fracture energy in Mode I, $G_{f}^{I}$ (pure tension), and the fracture energy of Mode IIa , $G_{f}^{I I a}$ (shear with no dilatancy allowed, which implies very high compression as explained below in more detail).

The evolution of the fracture work $W^{c r}$, is defined in the following incremental form.

$$
d W^{c r}=\left\{\begin{array}{cc}
\boldsymbol{\sigma}_{\mathrm{J}} \cdot d \mathbf{r}^{c r} & \text { if } \sigma_{n} \geq 0 \\
\left(|\tau|+\sigma_{n} \tan \phi\right)\left|d r_{t}^{c r}\right| & \text { if } \sigma_{n}<0
\end{array}\right.
$$

where $d \mathbf{r}^{c r}$ represents the increment of relative "crack" (plastic) opening displacements, with normal and tangential components $\left(d r_{n}^{c r} d r_{t}^{c r}\right)$ representing the crack opening and slip. The evolution of the fracture yield surface is described as follows. The fracture surface starts contracting and the stresses decrease with crack opening, so that the updated stress point remains always on the cracking surface. For an initial fracture surface, represented by curve "0" in Fig. 5, its final configuration will depend on the specific fracture mode. The only kinematic condition for a fully developed crack in pure tension (Mode I) requires normal separation of the two sides of the interface to be allowed. Due to material heterogeneity the cracking surface is rough and the final fracture yield surface is a hyperbola with its vertex at the origin, shown by curve "1" in Fig. 5. The other limit condition corresponds to cracking under shear and very high compression with no dilatancy, called "asymptotic mixed mode" or Mode IIa (Carol and Prat, 1990). In this second fracture mode, slip occurs in the tangential direction with no dilatancy allowed, and the final fracture yield surface is defined by a pair of straight lines expressing pure frictional behaviour (curve "2" in Fig. 5). In shear-compressoin loading conditions, the amount of dilatancy developed by the constitutive model corresponds to the proportion of crack plastic opening versus plastic slip ("flow rule"). The effect of vanishing dilatancy for high compression on the interface plane is obtained by reducing the normal component of the plastic flow rule for higher compression conditions, and this defined via parameter $\sigma_{d i l}$, which has the physical meaning of the value of normal compression stress value for which the model dilatancy would be totally suppressed.

It has to be emphasized that the constitutive law just described, corresponds to the behaviour of the zero-thickness interface elements themselves, but not necessarily to the behaviour of a rock specimen. In a micromechanical calculation, interface elements will be inserted along a considerable number of mesh lines, with many continuum elements in between, and multiple options of complex zig-zag cracking paths, including phenomena such as coalescence, bridging and branching. This causes the overall behaviour of the rock specimen to potentially show much higher complexity, progressivity and richness than the interface constitutive law itself.

\subsection{Automatic grain-removal algorithm}

One of the most sensitive developments in the sand production modelling is the grain extraction criterion. The methodology implemented for this purpose was based on (i) definition of the crack failure criterion (zero-thickness interface element failure), and (ii) definition of a criterion for removing a grain or set of grains.

The criterion of crack failure was developed using the internal variable of the interface constitutive model which consists of the energy dissipated in fracture process $\left(W^{c r}\right)$. This energy normalized with respect to the fracture energy parameter $G_{f}^{I}$ is compared to a threshold value, typically fixed to 0.7 , which is indicative of severe tensile degradation of the interface. Note that for an interface element to be marked as totally cracked, the following condition must be fulfilled at all its Gauss points,

$$
\frac{W^{c r}}{G_{f}^{I}} \geq 0.7 \Rightarrow \text { failure }
$$

Once the cracked interfaces are identified, a criterion for grain extraction is utilized, as explained in the followings lines. This procedure consists of removing the grains or groups of grains that are isolated from the medium by the fractured interface elements that start and end at the free surface of the inner cavity. The procedure has been automated with the inclusion of a module in the DRAC code (Prat et al., 1993) that checks the cracking and extraction criteria at the end of each incremental step. 
Figure 6 summarizes the different steps involved in the sanding algorithm:

A. Tree algorithm over cracked interfaces. This algorithm looks for any path of cracked interfaces that isolates a part of the discrete domain from the rest of the domain. First, the interfaces with nodes on the inner perforation boundary are checked to detect if they are cracked. Once this criterion is satisfied, a tree algorithm is used to check for any path of cracked fractures that leads to another node of the inner surface, different from the initial one (Fig. 6b). In the case of finding a fracture that isolates a part of the domain, then an algorithm is activated to detect the grains to be eliminated. If several paths are found with one inside the other, the algorithm selects the maximum envelope.

B. Elimination of grains. In case that any crack path exists that isolates a grain or group of grains ("breakout"), the removal algorithm is started (Fig. 6c). This automatic algorithm is based on the excavation procedure already existing in DRAC which can be divided in two steps:

(i) Evaluation of excavation forces $\left(F_{\text {exc }}\right)$. The excavation forces are computed using the appropriate integral of stress over the removed (excavated) domain $\left(\Omega_{r}\right)$ (Eq. (5)). The computation of equivalent nodal forces $\left(F_{\text {exc }}\right)$ due to excavation is only applied to existing nodes. Due to the fact that from the viewpoint of flow the excavation procedure takes place in steady state conditions, the evaluation of internal forces can be carried out directly in terms of the effective stress.

$$
F_{e x c}=\int_{\Omega_{r}} B^{\top} \boldsymbol{\sigma}^{\prime} d \Omega
$$

(ii) Application of excavation forces. The excavation forces are assembled into the load vector (or right hand side vector) and are applied in small increments.

C. Generation of data files for the subsequent calculations. These are the files indicating which elements have to be removed in the excavation process, and what forces have to be applied on the remaining nodes. A special situation may be encountered when, during the application of the excavation forces corresponding to a breakout, and before they may be completely applied, a new crack path trajectory is identified that leads to a new breakout. In this case the elements of the new breakout are removed, and the forces remaining to be applied in the previous breakout are accumulated to the new excavation forces. In the case of hole failure this process may never stop until grains removed reach the limit of the mesh domain.

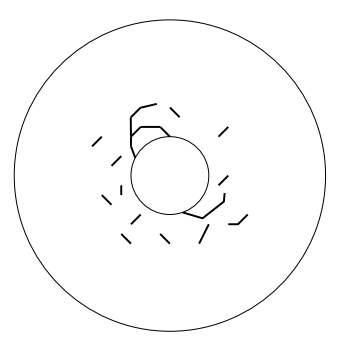

a) Detect failed interfaces

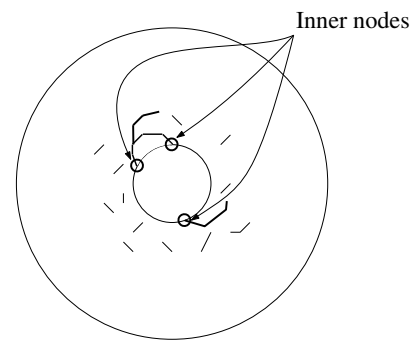

b) Tree algorithm

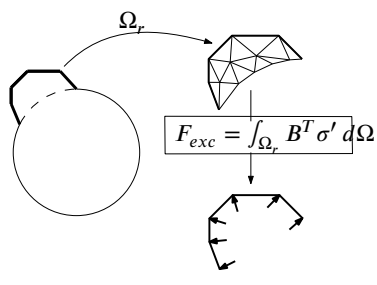

c) Removal algorithm

Figure 6: Simplified scheme of the sand production methodology.

In order to improve the performance of the procedure, a hierarchical model of the mesh geometry including grains and interfaces is generated at the beginning of the calculation, which contains the list of connectivities of joints and grains.

Additional details of this approach, including other interesting features such as brittle-ductile transition and intrinsic size effect, may be found in Garolera et al. (2019).

\section{Application to a TWC test}

This section includes the application of the approach described to calibrate the model using real data and predict and compare the results with thick wall cylinder tests data. For this purpose, real data was made available from samples recovered from a well with potential sanding problems. The material to be modelled is a cemented granular sandstone rock with calcareous matrix (mixture of cement and small particles that are found between the grains). Three thick wall cylinder tests were performed as well as several characterization and calibration tests. This study has focused on the simulation of two of those TWCs (the third one collapsed without showing sand production until complete failure). Data of two triaxial tests performed on cores from the same well and depths as the samples used for the TWCs has been used for the calibration of the model.

In summary, the simulation consists of two parts: first a calibration procedure was performed in order to reproduce as close as possible the macroscopic behaviour shown in triaxial tests. In the second part, with the parameters obtained above, a simulation of TWC was performed, and the results were compared with the experimental data. 
Table 1: Material properties of continuum.

\begin{tabular}{|c|c|c|c|c|}
\hline \multicolumn{2}{|c|}{ Parameter } & \multicolumn{2}{|l|}{ Value } & Units \\
\hline $\mathrm{E}$ & Young's modulus & 34.0 & 13.66 & $\mathrm{GPa}$ \\
\hline$\nu$ & Poisson's ratio & 0.27 & 0.15 & - \\
\hline
\end{tabular}

\subsection{Material characterization}

An important point of the analysis is the material calibration due to the fact that microstructural parameters have to be inferred from the macroscopic behaviour and measurements. For this purpose a numerical test similar to the calibration test was performed.

The first assumption was made on the grain size, which was fixed to be $0.6 \mathrm{~mm}$ as a first attempt. Results already presented in Garolera et al. (2019) showed that the simulation of TWC tests does not seem to be very sensitive to the grain size. The second assumption was the elastic isotropic behaviour of the continuum elements. Due to the lack of specific information about mechanical properties of individual grains (which would probably requiere very specialised techniques such as nanoindentation test), the elastic parameters of the grains were taken equal to the ones used in previous studies, which were based on typical values for the Red Wildmoor Sanstone (Papamichos et al., 2000). These values are given in Table 1.

Additionally, the same table shows the values of elastic parameters for the overall equivalent material (macroscopic values), which were obtained numerically from the displacements applied and resulting forces on the overall specimen, in elastic calculations. These values, turn out perfectly in range with the average values obtained experimentally in the triaxial tests, performed on cylindrical specimens of the same dimensions as those used for TWC tests $(76 \mathrm{~mm} \times 38 \mathrm{~mm}), \mathrm{E}=9.21 \mathrm{GPa}$ with std $\pm 6.96 \mathrm{GPa}$ and $\nu=0.15$ with std \pm 0.04 , which were obtained for selected sections of the linear parts of ascending branches of triaxial tests curves. Note that the overall equivalent parameters, aside from the elastic grains, also depend on the interface stiffness values which are discussed next.

Regarding the mechanical parameters of the interface elements, interface stiffness coefficients have been assigned to better fit the test data. In this case these parameters have not been interpreted merely as penalty coefficients, because their deformability is accepted to correspond to the deformation of the cementing matrix material, which is in this way represented by the interface behaviour. As already explained, interface elements are inserted along all potential crack lines in the mesh. Mechanically speaking, with this configuration the way in which interface and grain deformability are combined basically corresponds to a series arrangement. Since the grains are assumed to be very stiff, the overall deformability will be determined by the interface stiffness value, which in this study is fixed in order to obtain the correct overall modulus.

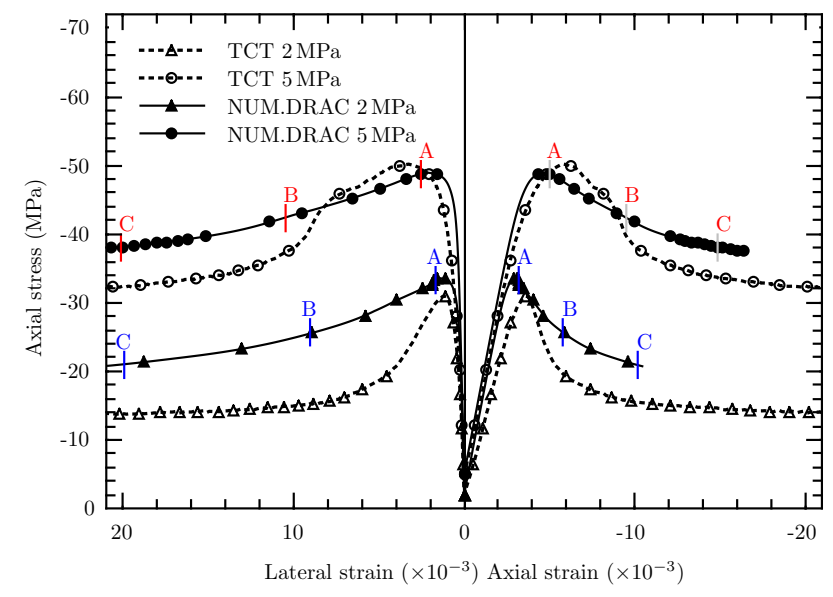

Figure 7: Comparison of model prediction with experimental data of triaxial tests.

In the absence of specific information, the tensile strength $\left(\chi_{0}\right)$ and cohesion $\left(C_{0}\right)$ values for the intra-granular interfaces have been taken equal to twice of those used for the inter-granular interfaces. The energies have been also assumed to be four times higher values for the intra-granular interfaces than the inter-granular ones. Finally, the confinement parameter at which dilatancy vanishes $\left(\sigma_{\text {dil }}\right)$ has been set at 10.0 MPa).

Based on the previous considerations and after some trial an error in order to get a good fit of the two triaxial curves available, the interface constitutive parameters used in the calculations are given in Table 2. In order to compare with the triaxial test data, a square specimen of material microstructure has been considered, in the assumption that the different aspect ratio does not imply any significant restrictions to the shear band-type cracks developing, which are reflected at the boundary and zigzag though the specimen with total similar crack length, provided the correct frictionless conditions are correctly assumed (see Ciancio et al. (2003)).

Figure 7 shows the two triaxial strain-stress curves obtained for the best fitting set of parameters, together with the experimental curves. In spite of the random nature of the samples, the results obtained with the microstructural model show a remarkable good fit. Both test results are obtained with exactly the same set of model parameters, by only changing the lateral confinement on the specimen $\left(\sigma_{0}=2 \mathrm{MPa}\right.$ or $\left.5 \mathrm{MPa}\right)$. Figure 8 shows the model prediction of the volumetric strain vs axial strain for the two experiments with different confining pressure. The results show clearly that the model is capable of capturing the transition from an initially compacting to a dilatant behaviour with shearing. The compacting regime increases with confining stress. Such transition in the volumetric behaviour is characteristic of cemented heterogeneous materials and in particular of weak sandstones.

Figures 9 and 10 show the displacement field and the 
Table 2: Material properties of interfaces.

\begin{tabular}{lllll}
\hline Parameter & & \multicolumn{2}{l}{ Value } & \multirow{2}{*}{ Units } \\
\cline { 3 - 4 } & & Inter-Grain & Intra-Grain & \\
\hline$K_{n}$ & Normal stiffness & $10^{8}$ & $10^{8}$ & $\mathrm{MPa} \cdot \mathrm{m}^{-1}$ \\
$K_{t}$ & Tangential stiffness & $10^{8}$ & $10^{8}$ & $\mathrm{MPa} \cdot \mathrm{m}^{-1}$ \\
$\chi_{0}$ & Tensile strength & 0.4 & 0.8 & $\mathrm{MPa}$ \\
$\tan (\phi)$ & Tangent of friction angle & $0.5773\left(30.0^{\circ}\right)$ & $0.5773\left(30.0^{\circ}\right)$ & \\
$c_{0}$ & Cohesion & 6.0 & 12.0 & $\mathrm{MPa}$ \\
$G_{f}^{I}$ & Energy mode I & $0.01 \cdot 10^{-3}$ & $0.04 \cdot 10^{-3}$ & $\mathrm{MPa} \cdot \mathrm{m}$ \\
$G_{f}^{I I a}$ & Energy mode IIa & $0.1 \cdot 10^{-3}$ & $0.4 \cdot 10^{-3}$ & $\mathrm{MPa} \cdot \mathrm{m}$ \\
$\sigma_{\text {dil }}$ & Sigma dilatation & 10.0 & 10.0 & $\mathrm{MPa}$ \\
\hline
\end{tabular}

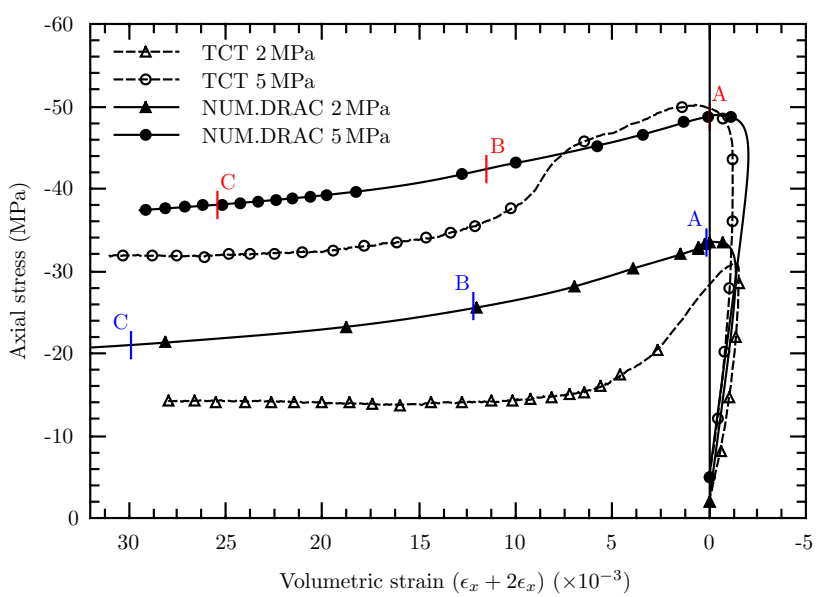

Figure 8: Model prediction of volumetric vs axial compression stress.

energy dissipated along interfaces for three stages of the loading (A, B and $\mathrm{C}$ in Figs. 7 and 8) of each of the two compression tests with $2 \mathrm{MPa}$ and $5 \mathrm{MPa}$ confinement, respectively. The figures show relatively different localization modes with a more brittle behaviour observed in the lower confinement case, where clear shear bands or/and shear cracks are observed whereas a more ductile behaviour is observed in the higher confinement case, in which the localization in the centre of the specimen is more diffuse and expands across a zone the shear failure in the form of "thick-bands". It is interesting to mention that the inclination of the shear cracks from the horizontal direction of the minimum compressive stress is approximately $60.0^{\circ}$ which is very close to the expected theoretical value of $\beta=45^{\circ}+(\phi+\psi) / 4$ (Vardoulakis, 1980). This crack direction does not depend on any mesh directionality as in the case of a classical continuum with material softening.

\subsection{TWC test simulation}

The simulation of sand production in TWC is based on the analysis of $2 \mathrm{D}$ cross-sections normal to the cylinder axis. Clearly, 2D analysis is a simplification of the $3 \mathrm{D}$ be- havior of real samples. However, given the computational effort of $3 \mathrm{D}$ calculations, this study is limited to $2 \mathrm{D}$ as a first step in the direction of developing a micromechanical description of the rock disaggregation processes involved in sand production. A full 3D version of the approach with comparison to the $2 \mathrm{D}$ calculations is therefore out of the scope of the present paper and subject of future research. The generation of the $2 \mathrm{D}$ discretized geometry follows the procedure described in Section 2.2. The geometry of the cross section of the TWC is presented in Fig. 11a), where the inner radius is $6 \mathrm{~mm}$ and the outer radius is about $18 \mathrm{~mm}$, therefore the ring thickness is $12 \mathrm{~mm}$. The height of the specimen is approximately $75.62 \mathrm{~mm}$ (ratio H:D 2.1:1) As observed in Fig. 11b), this thickness fits more than 20 grains. Note that in previous studies of the authors (Garolera et al., 2005; Garolera, 2017; Garolera et al., 2019), TWC models were composed of two domains, one discrete and one continuous. The area near the perforation was discretized according to the methodology described above and was denoted as the discrete subdomain. A second area, composed only of continuum elements, was used to ensure the continuity of the solution to the domain boundary. This part was denoted as continuous sub-domain. This methodology was satisfactory because it allowed to capture the fracture phenomena near the perforation and at the same time lightened the calculation by reducing the number of degrees of freedom. In the above mentioned previous studies, this simplification was adopted because the fracture zone was far from the external boundary. The ratio of external/internal radius was approximately 20/1. However, in the current analysis, this simplification can not be accepted due to the reduction in the ratio between the external/internal radius, which is now $3 / 1$ (see Fig. 12).

The resulting mesh has 47211 nodes, 15945 continuum elements and 23210 zero-thickness interface elements (Fig. 11b-c). The model was loaded with increasing external lateral stresses, in order to simulate the increase of the confining stresses in the TWC tests, which in turn is intended to simulate the increase of effective stress around a perforation that takes place due to wellbore drawdown and reservoir depletion. 

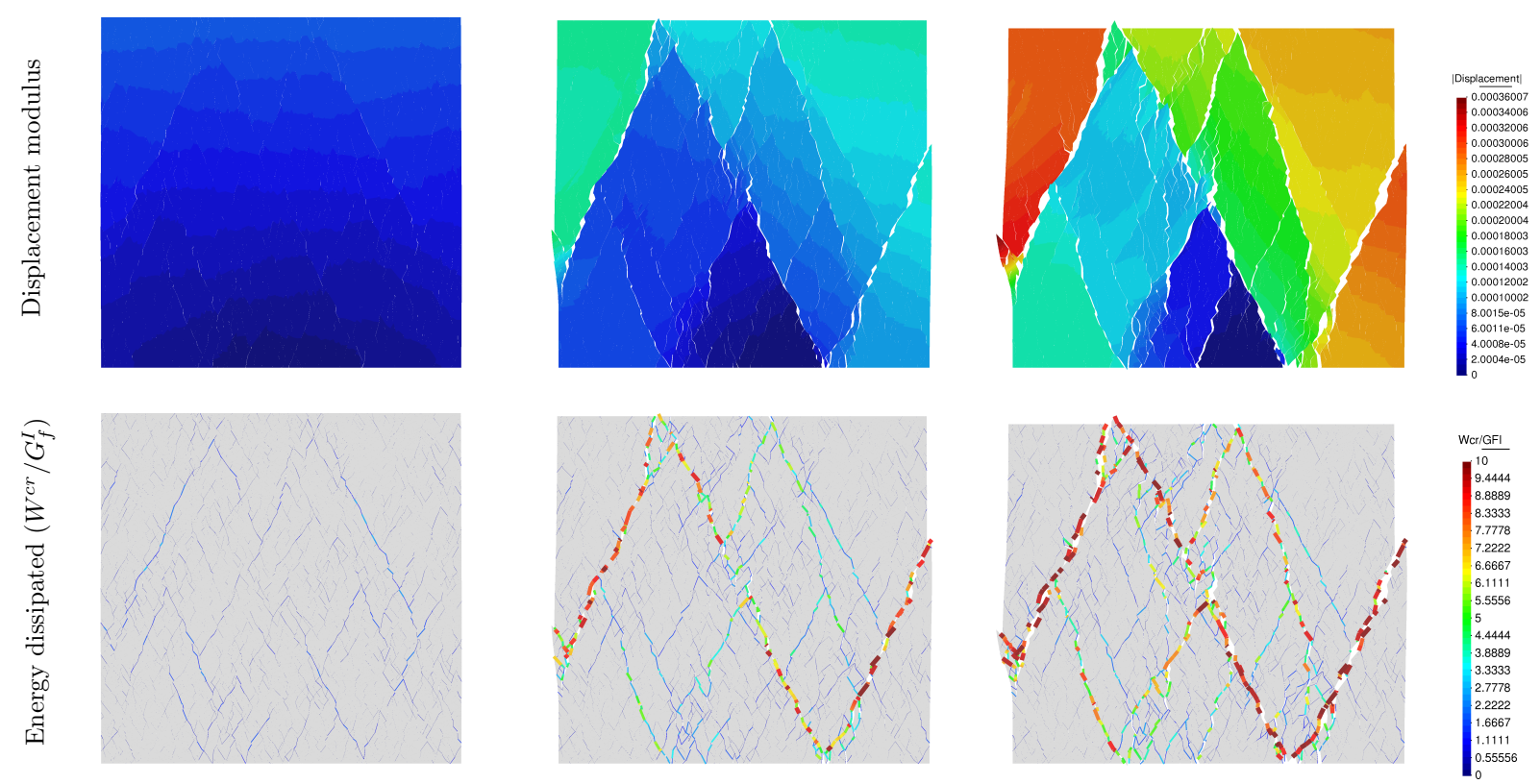

A) Axial strain $3 \times 10^{-3}$

B) Axial strain $6 \times 10^{-3}$

C) Axial strain $10 \times 10^{-3}$

Figure 9: Material characterization: results of compression test with $2 \mathrm{MPa}$ confinement: top, displacement field $(\mu \mathrm{m})$; and bottom, normalized energy dissipated along interface elements $\left(W^{c r} / G_{f}^{I}\right)$. The results were plotted over a deformed mesh (magnification $\times 5)$.
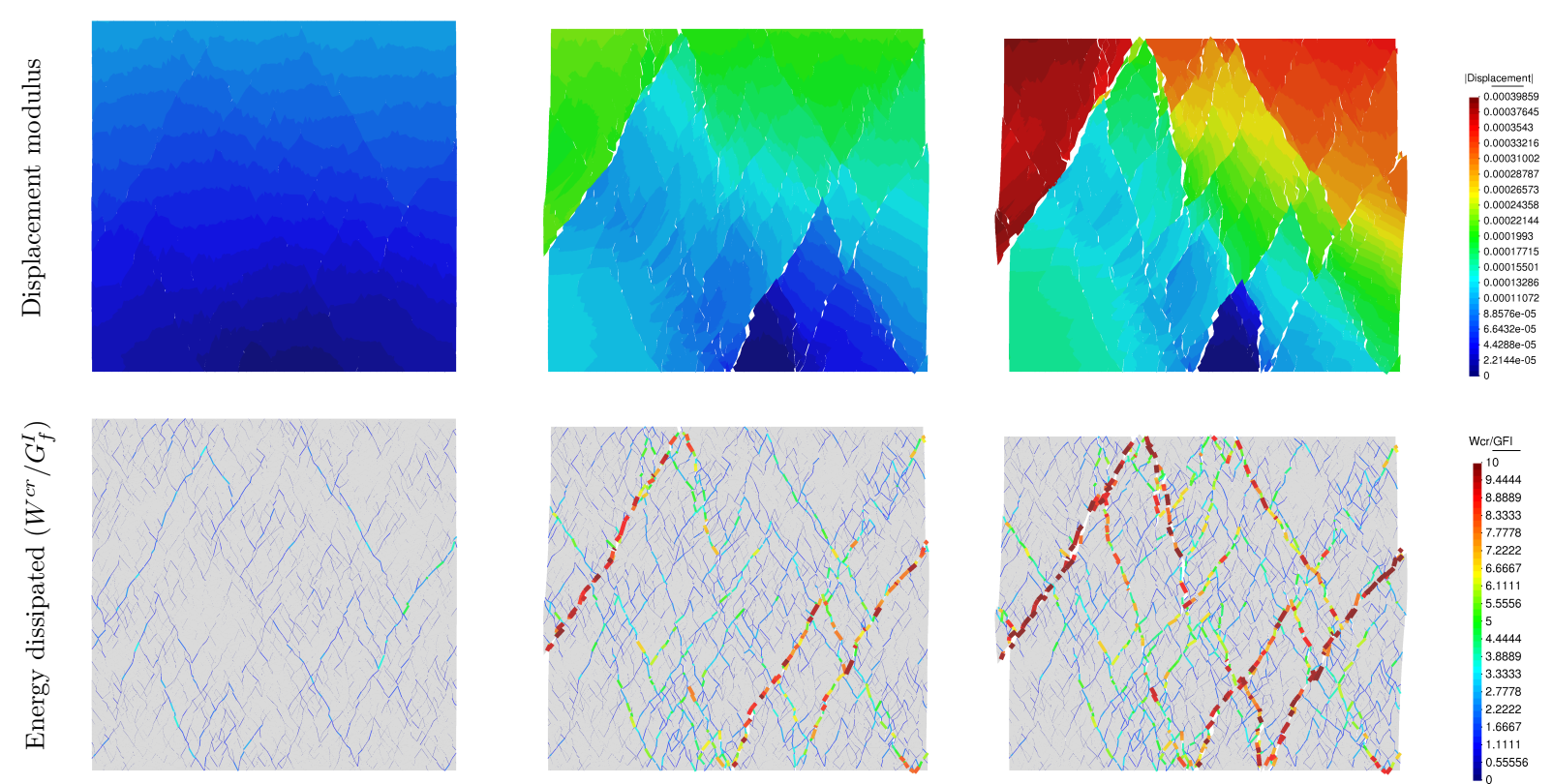

A) Axial strain $5 \times 10^{-3}$

B) Axial strain $10 \times 10^{-3}$

C) Axial strain $15 \times 10^{-3}$

Figure 10: Material characterization: results of compression test with $5 \mathrm{MPa}$ confinement: top, displacement field $(\mu \mathrm{m})$; and bottom, normalized energy dissipated along interface elements $\left(W^{c r} / G_{f}^{I}\right)$. The results were plotted over a deformed mesh (magnification $\times 5)$. 


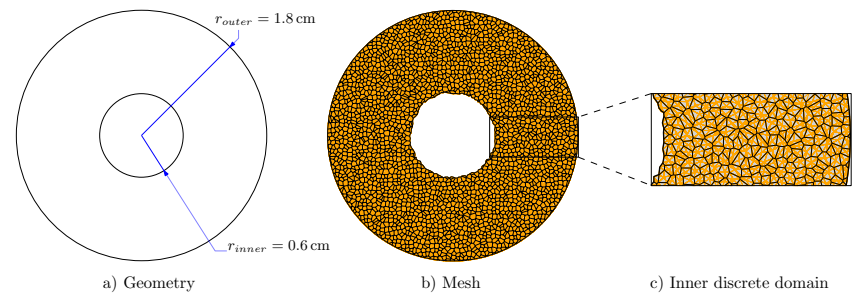

Figure 11: Geometry used to model the thick wall cylinder tests.

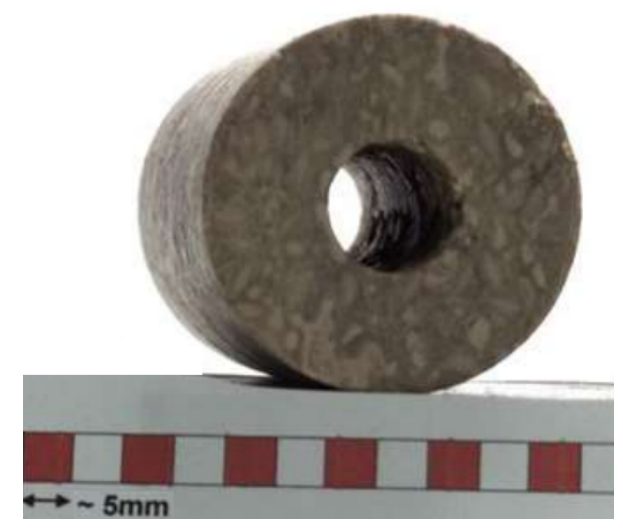

Figure 12: Photograph of the EXP-1 sample before testing.

In the TWC tests simulated, specimens such as the one shown in Fig. 12 are subject to purely mechanical spherical loading (same stress value applied on the top and bottom cylinder ends, as well as on the lateral surface), while a fluid is circulating through the inner whole with the only purpose of removing from the sample the disaggregated material. The mass of material taken away by the fluid is then measured and the accumulated values are plotted against the applied spherical stress.

It was found in TWC tests that sanding in consolidated rock samples involves, first the increase in the effective stresses that induces failure near the cavity, and then the flow transports the loose sand grains (Tronvoll et al., 1993; Papamichos and den Hoek, 1995; Nicholson et al., 1998).

The results of three of such experimental tests are represented in Fig. 13. The three sandstone specimens denoted as TWC-1, TWC-2 and TWC-3 were obtained from the same rock formation but slightly different depths. Note that each curve starts when sand is first detected in the outgoing fluid. The typical curve shows a positive slope indicating increasing amount of sand produced for increasing pressure, and the slope is progressively increasing until the curve becomes vertical, indicating hole failure. Note, however, that not all the curves exhibit all three stages, for instance TWC-3 goes immediately vertical from the beginning indicating hole collapse at the onset of sand production. In contrast, TWC-1 shows a slight hardening curve, and TWC-2 a much more progressive response. Another difference is in the total amount of sand produced in each test, although this may be not so indicative because, once the hole collapse process starts, the outflow of material is continuous and the total amount of sand measured may depend on how long it has taken to stop each test since the collapse failure was detected. A final remark concerns the different values of collapse pressure measured for each test, which are 23,38 and $55 \mathrm{MPa}$ in spite of being similar samples from the same formation. The difference is attributed to natural randomness of the rock constituents, combined with the high sensitivity to small variations of geometry or parameters, which are typically associated to highly non-linear instability processes such as the hole collapse in TWC tests.

The results of the numerical simulation of thick wall cylinder test are presented in Fig. 13, together with the experimental data of the three tests performed on similar samples. The pressure value corresponding to the onset of sanding in the calculation starts at $23 \mathrm{MPa}$ pressure which is similar to the TWC-3 collapse pressure, but lower than the initial sanding pressures in both experimental tests TWC-1 and TWC-2 (of 38 and $55 \mathrm{MPa}$ ) at which the first signs of sanding were detected. This difference may be explained by the experimental difficulties to define and determine the exact initiation point (which may have been lower than shown in the curves for all the tests), while in numerical simulations all grains detached are strictly recorded and accounted for.

With regard to the collapse load itself, the value computed turns out very close to the TWC-1 experiment, which is in the middle of the experimental range of the three tests.

The second essential aspect is the quantification of sand produced in the tests. With regard to this, the experimental tests show even more dispersion than with collapse pressures although, as discussed above, this may be not so significant once the collapse has started since it may depend on how long it has taken to stop the test.

With regard to the micromechanical analysis, the evaluation of amount of sand produced would be quite straight forward in 3D (volume of grains detached), but is not so trivial in the case of $2 \mathrm{D}$ calculations as developed in this paper. In 2D, what follows immediately from the analysis is the surface area lost in the specimen cross-section, but conversion to rock volume and mass requires to assume an out-of-plane dimension. One possible procedure for that has been developed and implemented as follows: in experimental tests it has been seen than cavities created by failures in the inner cylinder wall often show an aspect ratio of same order of magnitude in longitudinal and transversal directions. Based on this observation, the size of those cavities has been measured on the computer plots of the horizontal cross-sections at each stage of the calculation, and the corresponding area surface lost has been used to obtain the lost volume, which has been later converted to mass via rock density. The results of this post-processing is also shown in Fig. 13, on the vertical side of diagram, same as for the experimental tests. 


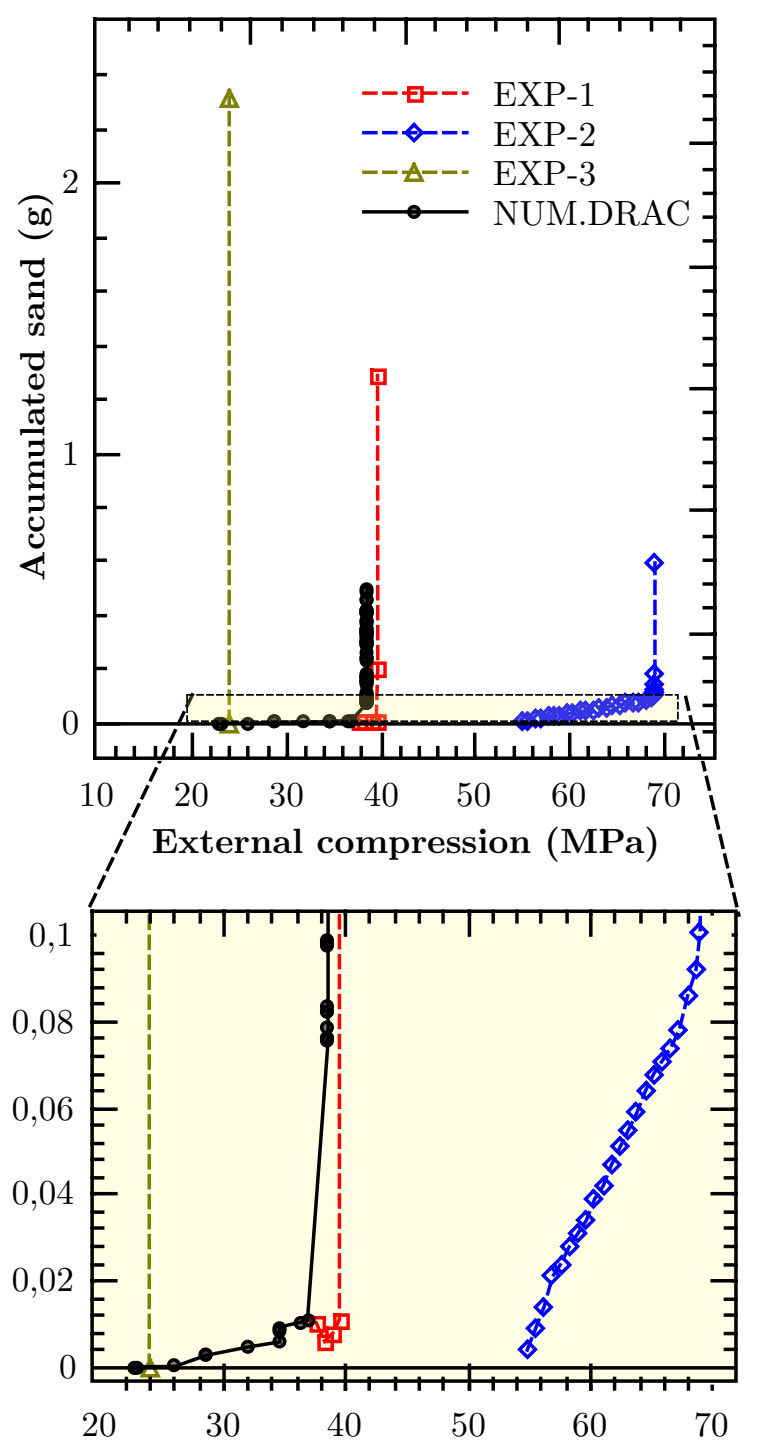

Figure 13: Comparison between numerical results and experimental data in terms of accumulated sand production vs external pressure.
Figures 14 and 15 depict the geometry evolution of the sanding process at each stage, as well as the fracture energy along remaining discontinuities and the maximum compressive stress at each point of the mesh, respectively. Note, however, that in the two figures, only the first two images of each sequence correspond to stable configurations for which all the previous excavation forces have been completely applied via converged calculations (see explanation at the end of Section 2.4). The remaining images correspond to unstable configurations for which, before becoming equilibrated, a new excavation process has been triggered. Consequently, stresses in Fig. 15 (except for the first two images, $a$ and $b$ ) correspond to states which for equilibrium would require (not only the external applied stress but also) the accumulated excavation forces which have remained unapplied. The deformation starts with localization in three areas near the cavity, which is consistent with bifurcation and localization theory that predicts warping, which in this case appears to be in mode 3 for very small holes (Papanastasiou and Vardoulakis, 1992; Zervos et al., 2001; Papanastasiou and Zervos, 2004). With increasing pressurization most of the damage is localized in two nearly diametrically opposed regions that form the familiar borehole breakout pattern.

It is worth mentioning that Fig. 15 shows that the area near the cavity is well in the softening regime as the maximum compressive stress, which is in the circumferential direction, has value much below the external pressure. The maximum compressive stress develops in the adjacent (green) area and has value of approximately two times the external pressure, as predicted by the theory of elasticity.

\section{Concluding remarks}

A sand-production prediction model based on a micromechanical approach with zero-thickness interface finite elements has been described. The proposed methodology reproduces the complex behaviour of the disagreggation of the heterogeneous material by using only very few micro and meso scales physical parameters that are calibrated at the macro-scale by reproducing the typical behaviour of compression element tests. Some general advantages of the model developed are: a) the complexity of the microstructural description and associated computational cost is compensated by a relatively simple constitutive formulation with a limited number of parameters with clear physical meaning, b) the results directly describe microstructural phenomena occurring in the material such as micro-crack initiation, development and coalescence, localization into macro-cracks, and material disaggregation and grain detachment, c) in uniaxial and triaxial compression, inclined shear-compression macro cracks are obtained with orientations close to those predicted by existing localization studies, d) as confinement is increased, the behaviour turns more ductile with a higher tendency of micro-cracks to remain distributed and lower tendency to 


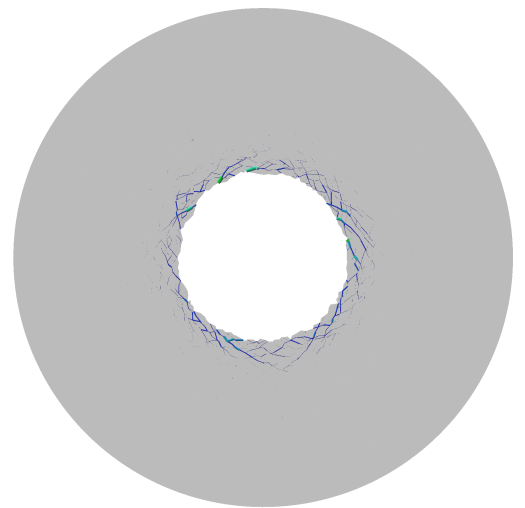

a) Stage $5\left(\sigma_{\text {ext }}=31.83 \mathrm{MPa}\right)$

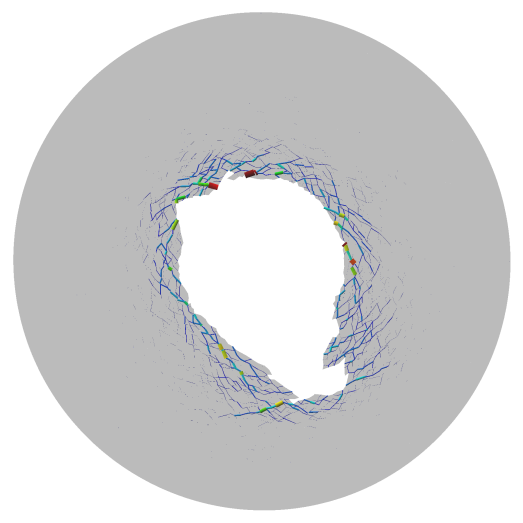

d) Stage $30\left(\sigma_{\text {ext }}=38.53 \mathrm{MPa}\right)$

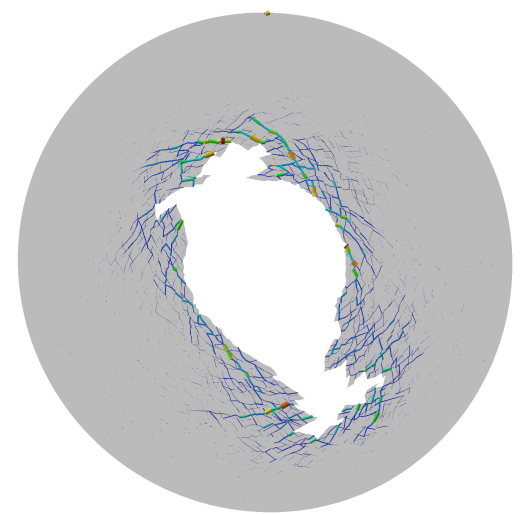

g) Stage $55\left(\sigma_{\text {ext }}=38.53 \mathrm{MPa}\right)$

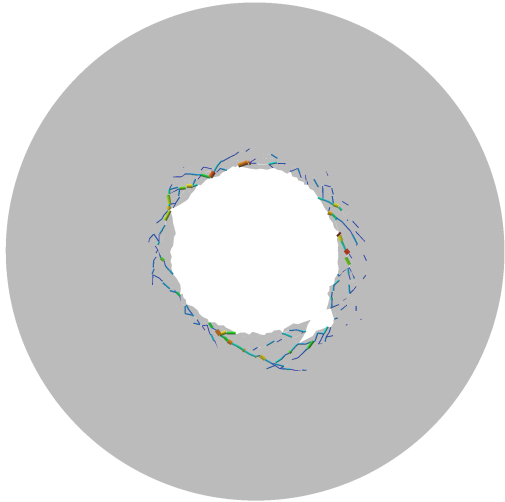

b) Stage $11\left(\sigma_{e x t}=38.53 \mathrm{MPa}\right)$

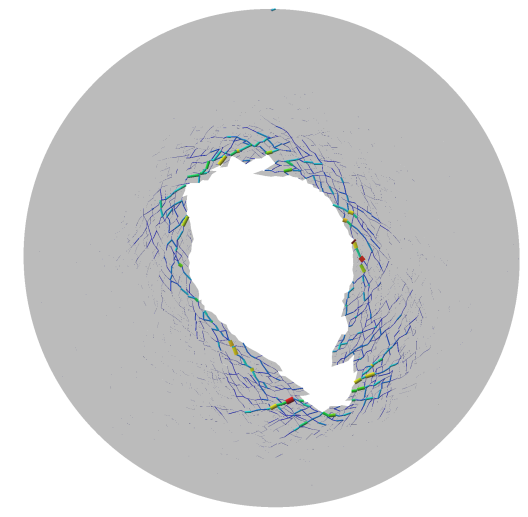

e) Stage $40\left(\sigma_{\text {ext }}=38.53 \mathrm{MPa}\right)$

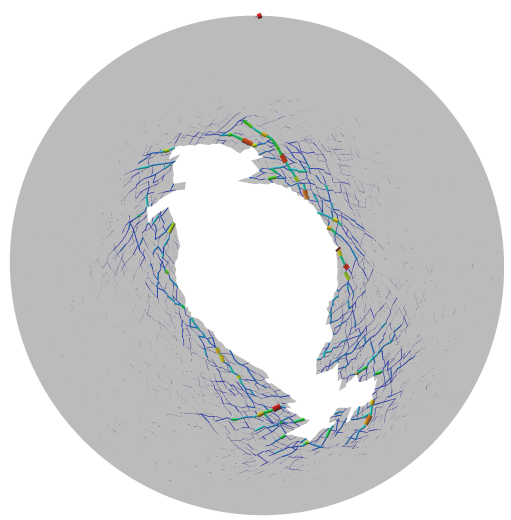

h) Stage $60\left(\sigma_{e x t}=38.53 \mathrm{MPa}\right)$

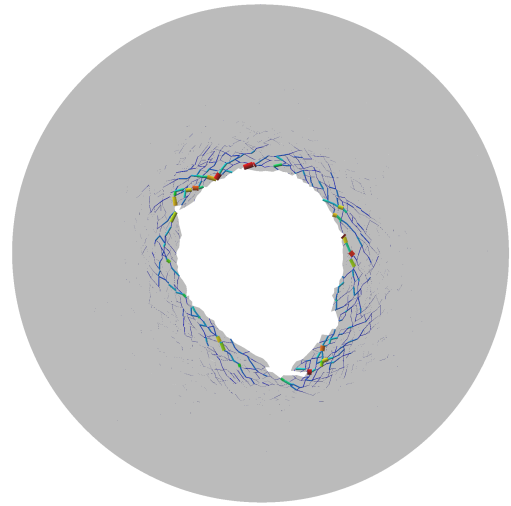

c) Stage $20\left(\sigma_{\text {ext }}=38.53 \mathrm{MPa}\right)$

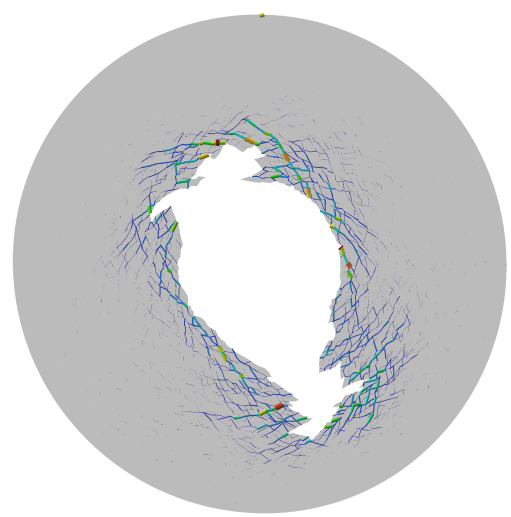

f) Stage $50\left(\sigma_{e x t}=38.53 \mathrm{MPa}\right)$

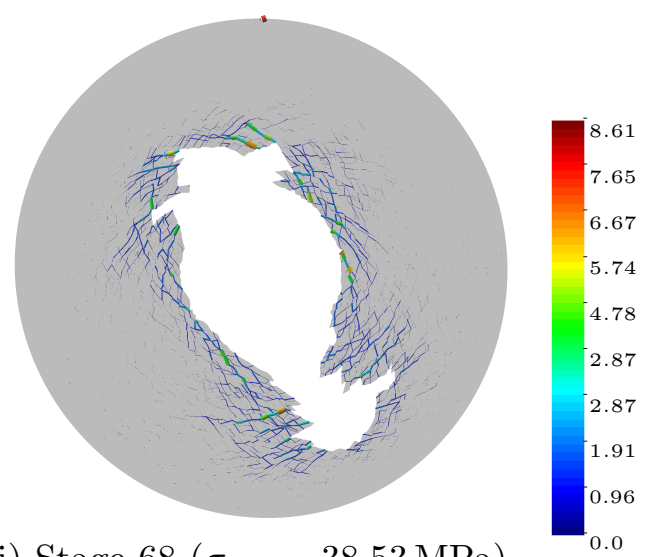

i) Stage $68\left(\sigma_{\text {ext }}=38.53 \mathrm{MPa}\right)$

Figure 14: Evolution of geometry and of $W^{c r} / G_{f}^{I}$ along the remaining interface elements. The line diagram is plotted on the deformed mesh (magnification $\times 2$ ). 


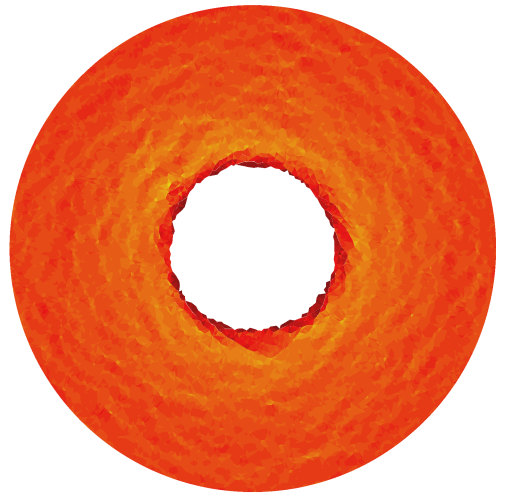

a) Stage $5\left(\sigma_{e x t}=31.83 \mathrm{MPa}\right)$

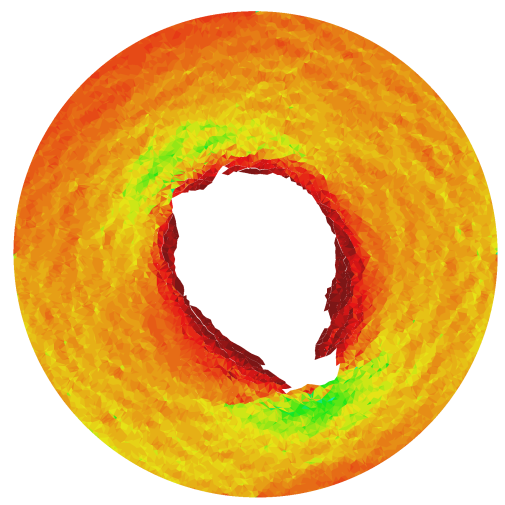

d) Stage $30\left(\sigma_{e x t}=38.53 \mathrm{MPa}\right)$

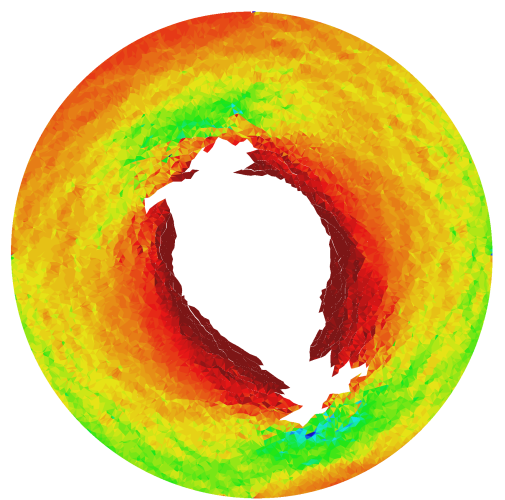

g) Stage $55\left(\sigma_{\text {ext }}=38.53 \mathrm{MPa}\right)$

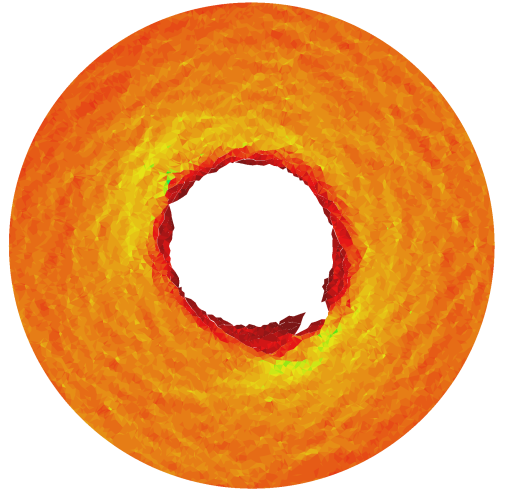

b) Stage $11\left(\sigma_{e x t}=38.53 \mathrm{MPa}\right)$

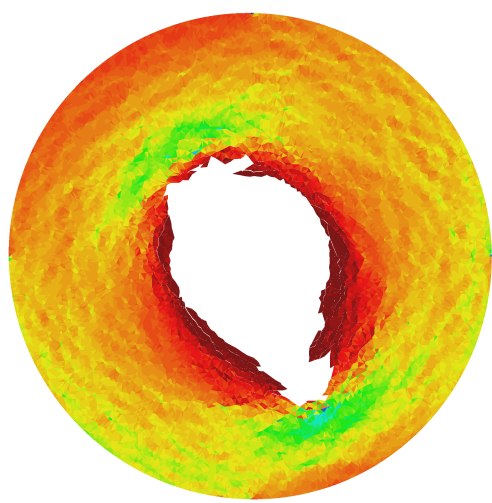

e) Stage $40\left(\sigma_{e x t}=38.53 \mathrm{MPa}\right)$

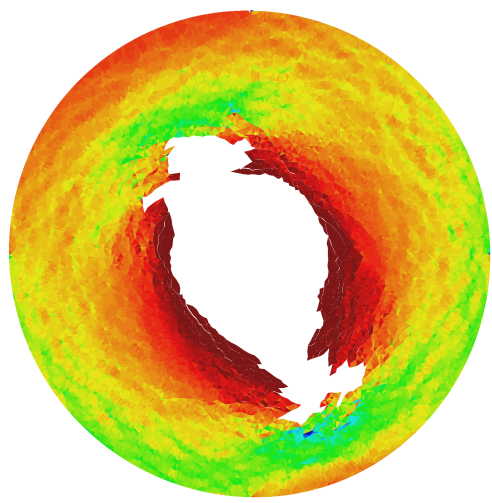

h) Stage $60\left(\sigma_{\text {ext }}=38.53 \mathrm{MPa}\right)$

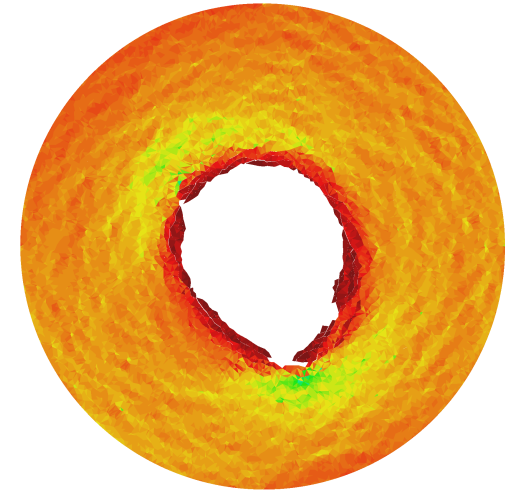

c) Stage $20\left(\sigma_{\text {ext }}=38.53 \mathrm{MPa}\right)$

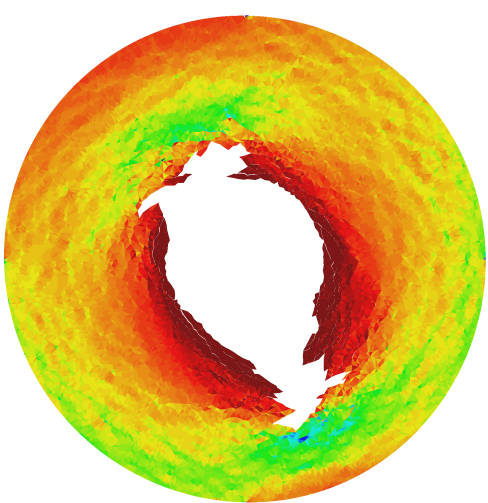

f) Stage $50\left(\sigma_{e x t}=38.53 \mathrm{MPa}\right)$

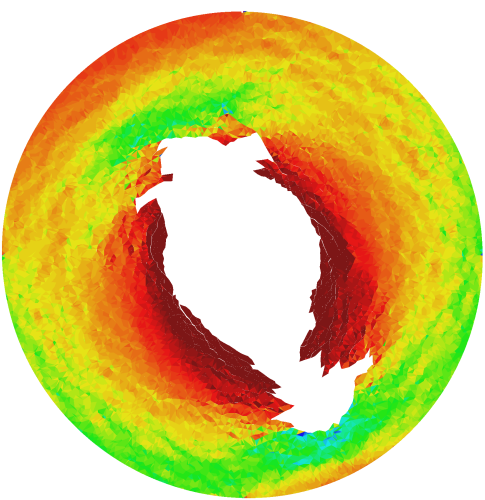

i) Stage $68\left(\sigma_{\text {ext }}=38.53 \mathrm{MPa}\right)$
(MPa)

1.0288
-11.648
-24.324
-37.001
-49.677
-62.354
-75.03
-87.707
-100.38
-113.06
-125.74
-138.41
-151.09
-163.77
-176.44
-189.12
-201.8
-214.47
-227.15

$-227.15$

Figure 15: Evolution of $\sigma_{\max }(\mathrm{MPa})$ in the continuum elements around the perforation. Contour fill plotted over deformed mesh (magnification $\times 2$ ). 
localize into macro-cracks, and e) in addition to the richness of micro-structural information, the resulting overall average stress-strain curves do also exhibit the main features expected in triaxial tests, such as realistic uniaxial compression behavior for zero confinement, peak load and overall ductility increasing with higher confinement, and initially compacting behavior evolving to dilation as failure is reached, among others.

As a first attempt of sanding prediction, the model is used for the simulation of thick wall cylinder tests, which is a common test in industry to evaluate rock susceptibility to sand production, and experimental results are available to compare the numerical predictions. The model parameters were calibrated by simulating two triaxial compression tests on similar reservoir cores. The results obtained are compared satisfactory with the results of thick wall cylinder tests on reservoir cores. The proposed methodology is very promising as it can predict not only predict the initiation of sanding but also can lead to a quantification of the produced sand volumes, which is a challenging formidable task due to continuous change of the geometry with the eroded material. So far, this quantification of the sand produced remains approximate due to the $2 \mathrm{D}$ nature of the calculations performed, which requires to estimate the "depth" of the eroded area, but this limitation will totally disappear with the future 3D extension of the approach.

\section{Acknowledgments}

The work was partially supported by research grants BIA2016-76543-R from MEC (Madrid), which includes FEDER funds from the European Union, and 2017SGR-1153 from Generalitat de Catalunya (Barcelona). The first author would like to thank the MEC (Madrid) for his FPU doctoral fellowship.

\section{References}

Bažant, Z.P., Planas, J., 1998. Fracture and Size Effect in Concrete and Other Quasibrittle Materials. New Directions in Civil Engineering, CRC Press.

Caballero, A., Carol, I., López, C.M., 2006. A meso-level approach to the $3 \mathrm{D}$ numerical analysis of cracking and fracture of concrete materials. Fatigue and Fracture of Engineering Materials and Structures 29(12), 979-991.

Caballero, A., Willam, K., Carol, I., 2008. Consistent tangent formulation for $3 \mathrm{D}$ interface modeling of cracking/fracture in quasi-brittle materials. Computer Methods in Applied Mechanics and Engineering 197(33-40), 2804-2822. doi:10.1016/j.cma.2008.01.011.

Carol, I., López, C.M., Roa, O., 2001. Micromechanical analysis of quasi-brittle materials using fracture-based interface elements. International Journal for Numerical Methods in Engineering 52, 193-215.

Carol, I., Prat, P., 1990. A statically constrained microplane model for the smeared analysis of concrete cracking, in: Bićanić, N., Mang, H. (Eds.), Computer-Aided Analysis and Design of Concrete Structures, Pineridge Press. pp. 919-930.

Carol, I., Prat, P., 1995. A multicrack model based on the theory of multisurface plasticity and two fracture energies, in: Computational Plasticity, COMPLAS IV, pp. 1583-1594.
Carol, I., Prat, P.C., López, C.M., 1997. Normal/shear cracking model: application to discrete crack analysis. Journal of engineering mechanics 123(8), 765-773.

Ciancio, D., López, C., Carol, I., Cuomo, M., 2003. New results in meso-mechanical modeling of concrete using fracture-based zerothickness interface elements, in: Bićanić, N., de Borst, R., Mang, H., Meschke, G. (Eds.), Computational Modelling of Concrete Structures, Balkema, St. Johann im Pongau (Austria). pp. 171177. ISBN 9058095633.

Garolera, D., 2017. Zero-thickness interface elements in petroleum geomechanics: sand production and hydraulic fracture. Ph.D. thesis. ETSECCPB (Barcelona School of Civil Engineering), UPC (Universitat Politècnica de Catalunya).

Garolera, D., Carol, I., López, C.M., 2011. Micromechanical analysis of damage and fracture in sandstone rock specimens, using zerothickness interface elements, in: Oñate, E., Owen, D., Peric, D., Suárez, B. (Eds.), Computational Plasticity XI - Fundamentals and Applications, COMPLAS XI, CIMNE. pp. 1222-1232.

Garolera, D., Carol, I., Papanastasiou, P., 2019. Micromechanical analysis of sand production. International Journal for Numerical and Analytical Methods in Geomechanics 43(6), 1207-1229. doi:10.1002/nag.2892.

Garolera, D., Lopez, C.M., Carol, I., Papanastasiou, P., 2005. Micromechanical analysis of the rock sanding problem. Journal of the Mechanical Behavior of Materials 16(1-2), 45-54. doi:10.1515/JMBM.2005.16.1-2.45.

Gens, A., Carol, I., Alonso, E., 1989. An interface element formulation for the analysis of soil-reinforcement interaction. Computers and Geotechnics 7, 133-151. doi:10.1016/0266-352X(89)90011-6. special Issue on Soil Reinforcement.

Goodman, R.E., Taylor, R.L., Brekke, T.L., 1968. A model for the mechanics of jointed rock. Journal of the Soil Mechanics and Foundation Division 94, 637-659.

Gravanis, E., Sarris, E., Papanastasiou, P., 2015. Hydro-mechanical erosion models for sand production. International Journal for $\mathrm{Nu}-$ merical and Analytical Methods in Geomechanics 39(18), 20172036. doi:10.1002/nag.2383.

Haimson, B.C., Herrick, C., 1989. Borehole breakouts and in situ stress, in: Rowley, J.C. (Ed.), Proc. Drilling symposium, ASME. pp. $17-22$.

Han, G., 2003. Rock Stability under Different Fluid Flow Conditions. PhD dissertation. Departament of Chemical Engineering, University of Waterloo. Canada. doi:10012/827.

Jensen, R., Preece, D., Cook, B., Williams, J., 2001. Modeling sand production with darcy coupled with discrete elements, in: et al., D. (Ed.), Comp. Meth. And Adv. In Geomech. Balkema, Rotterdam, p. 819-822.

Li, L., Papamichos, E., Cerasi, P., 2006. Investigation of sand production mechanisms using dem with fluid flow, in: van Cotthem, A., Charlier, R., Thimus, J., Tshibangu, J. (Eds.), Eurock 2006: Multiphysics Coupling and Long Term Behaviour in Rock Mechanics, International Society for Rock Mechanics. Taylor \& Francis. p. 241-247. doi:10.1201/9781439833469.ch33.

López, C.M., 1999. Análisis microestructural de la fractura del hormigón utilizando elementos finitos tipo junta. Aplicación a diferentes hormigones. Ph.D. thesis. Barcelona School of Civil Engineering, Universitat Politècnica de Catalunya.

López, C.M., Carol, I., Aguado, A., 2008. Meso-structural study of concrete fracture using interface elements. i: numerical model and tensile behavior. Materials and Structures 41(3), 583-599.

Morita, N., 2004. Well orientation effect on borehole stability, in: SPE (Ed.), SPE Annual Technical Conference and Exhibition, pp. 449-460. doi:10.2118/89896-MS.

Nicholson, E., Goldsmith, G., Cook, J., 1998. Direct observation and modeling of sand production processes in weak sandstone, in: SPE/ISRM Eurock 98 Conference, Society of Petroleum Engineers. pp. 97-106. doi:10.2118/47328-MS.

Papamichos, E., 2010. Borehole failure analysis in a sandstone under anisotropic stresses. International Journal for Numerical and Analytical Methods in Geomechanics 34(6), 581-603. doi:10.1002/nag.824. 
Papamichos, E., Furui, K., 2019. Analytical models for sand onset under field conditions. Journal of Petroleum Science and Engineering 172, 171-189. doi:10.1016/j.petrol.2018.09.009.

Papamichos, E., den Hoek, P.J.V., 1995. Size dependency of castlegate and berea sandstone hollow-cylinder strength on the basis of bifurcation theory, in: The 35th U.S. Symposium on Rock Mechanics (USRMS), Reno, Nevada, Balkema. pp. 301-306.

Papamichos, E., Stavropoulou, M., 1998. An erosion-mechanical model for sand production rate prediction. International Journal of Rock Mechanics and Mining Sciences 35(4), 531-532. doi:10.1016/S0148-9062(98)00106-5.

Papamichos, E., Tronvoll, J., Vardoulakis, I., Labuz, J.F., Skjaerstein, A., Unander, T.E., Sulem, J., 2000. Constitutive testing of red wildmoor sandstone. Mechanics of Cohesive-frictional Materials 5(1), 1-40. doi:10.1002/(SICI)1099-1484(200001)5:1¡1::AIDCFM74¿3.0.CO;2-H.

Papamichos, E., Vardoulakis, I., Tronvoll, J., Skjaerstein, A., 2001. Volumetric sand production model and experiment. International Journal for Numerical and Analytical Methods in Geomechanics 25(8), 789-808. doi:10.1002/nag.154.

Papanastasiou, P., Thiercelin, M., 2011. Modeling borehole and perforation collapse with the capability of predicting the scale effect. International Journal of Geomechanics 11(4), 286-293. doi:10.1061/(ASCE)GM.1943-5622.0000013.

Papanastasiou, P., Vardoulakis, I., 1989. Bifurcation analysis of deep boreholes: II. Scale effect. International Journal for $\mathrm{Nu}-$ merical and Analytical Methods in Geomechanics 13(2), 183-198. doi:10.1002/nag.1610130206.

Papanastasiou, P., Vardoulakis, I., 1992. Numerical treatment of progressive localization in relation to borehole stability. International Journal for Numerical and Analytical Methods in Geomechanics 16(6), 389-424. doi:10.1002/nag.1610160602.

Papanastasiou, P., Zervos, A., 2004. Wellbore stability analysis: From linear elasticity to postbifurcation modeling. International Journal of Geomechanics 4(1), 2-12. doi:10.1061/(ASCE)15323641(2004)4:1(2).

Prat, P., Gens, A., Carol, I., Ledesma, A., Gili, J., 1993. DRAC: A computer software for the analysis of rock mechanics problems, in: Liu, H. (Ed.), Application of Computer Methods in Rock Mechanics in Rock Mechanics, Shaanxi Science and Technology Press. pp. 1361-1368.

Rahmati, H., Jafarpour, M., Azadbakht, S., Nouri, A., Vaziri, H., Chan, D., Xiao, Y., 2013. Review of sand production prediction models. Journal of Petroleum Engineering doi:10.1155/2013/864981.

Rots, J., 1988. Computational Modelling of Concrete Fracture. Phd thesis. TU Delft.

Segura, J.M., Carol, I., 2008a. Coupled HM analysis using zerothickness interface elements with double nodes. Part I: Theoretical model. International Journal for Numerical and Analytical Methods in Geomechanics 32, 2083-2101. doi:10.1002/nag.735.

Segura, J.M., Carol, I., 2008b. Coupled HM analysis using zerothickness interface elements with double nodes-Part II: Verification and application. International Journal for Numerical and Analytical Methods in Geomechanics 32, 2103-2123. doi:10.1002/nag.730.

Stavropoulou, M., Papanastasiou, P., Vardoulakis, I., 1998. Coupled well bore erosion and stability analysis. International Journal for Numerical and Analytical Methods in Geomechanics 22, 749-769.

Tronvoll, J., Papamichos, E., Kessler, N., 1993. Perforation cavity stability: Investigation of failure mechanisms, in: Proc. Symp. Hard Soils, Soft Rocks, Balkema. p. 1687-1693.

Vardoulakis, I., 1980. Shear band inclination and shear modulus of sand in biaxial tests. International Journal for Numerical and Analytical Methods in Geomechanics 4, 103-119. doi:10.1002/nag.1610040202.

Vardoulakis, I., Stavropoulou, M., Papanastasiou, P., 1996. Hydromechanical aspects of sand production problem. Transport in Porous Media 22, 225-244.

Zervos, A., Papanastasiou, P., Vardoulakis, I., 2001. Modelling of localisation and scale effect in thick-walled cylinders with gradient elastoplasticity. International Journal of Solids and Structures 38(30-31), 5081-5095. doi:10.1016/S0020-7683(00)00337-1. 